Sérgio Tonini Button

sergio1@fem.unicamp.br

University of Campinas

Department of Materials Engineering

13083-970 Campinas, SP, Brazil

\section{Numerical and Experimental Analysis of Lubrication in Strip Cold Rolling}

In this work an analytical model based on the slab method was built to analyze the lubrication during cold rolling of aluminum strips. Some process variables were studied like the rolling speed, the cross-section reduction, and lubricant viscosity. Numerical results are presented for pressure variation and film thickness at the inlet and work zones. The loads necessary to separate the rolls are also estimated. Some experimental results are shown for the surface roughness of the rolled products. It is shown that analytical results are in good accordance to experimental results, and that rolling pressure, lubricant film thickness and surface roughness are strongly influenced by rolling conditions, especially the lubricant viscosity and the area reduction.

Keywords: strip rolling, lubrication, slab method, aluminum

\section{Introduction}

Numerical and analytical modeling of cold rolling is very important to define ideal processing conditions which minimize the excessive metallic contact between rolls and rolled strips.

Therefore, it is possible to reduce or even avoid some effects of this contact like heating and wear of the rolls, the worst superficial quality of the products, the loss of productivity, and the reduction of workability. In recent years, many authors have studied the lubrication during strip rolling and presented mathematical models to represent it, like Louaisil et al. (2009), Wei et al. (2009), Singh et al. (2008) and Kosasih and Tieu (2007).

This work presents a mathematical model based on the "slab method" built to analyze the lubrication during cold rolling of aluminum strips. Some variables of the process were studied like the rolling speed, the cross-section reduction, and lubricant viscosity to evaluate their influence on the pressure distribution and film thickness of the lubricant, and on the surface roughness of cold rolled strips.

At first, it could be estimated that the lubrication regime related to a minimum friction would be the thick film regime obtained with high viscosity lubricants.

Dow et al. (1975) stated that it is not necessarily true that films thick enough would be established with low viscosity lubricants if adequate rolling speeds are chosen.

If the lubricant does not show the properties necessary to establish a hydrodynamic regime, the film will be broken and reestablished and the process will become unstable and hard to control.

Some authors presented some theories to model the lubrication of rolling at high speeds. Cheng (1966) applied the elastohydrodynamic theory to evaluate the thickness of the lubricant film at the entrance of the work region. Bedi et al. (1968) applied the energy method to calculate the film thickness in the work region, but they did not consider the effect of the viscosity variation due to pressure and temperature gradients.

Wilson and Walowit (1971) combined Reynolds equations and the plasticity theory to define a hydrodynamic theory, but they assumed that the process was isothermal.

Dow et al. (1975) extended that theory by including the effects of viscous shearing and lubricant heating, but they did not consider the influence of the temperature increase in the work region on the film thickness.

Wilson and Murch (1976) presented a thermo-plastohydrodynamic model based on the slab method that included the thermal effects on the film formation in the inlet zone, on the friction and on the variation of the film thickness in the work region.

In this work it was built a model based on Wilson and Murch (1976) theory considering some additional aspects like strain

Paper accepted August, 2010. Technical Editor: Anselmo E. Diniz hardening of the strip and the influence of surface roughness (of the rolls and strips) on the pressure gradient and the film thickness during cold rolling.

This model also evaluates the roll separation load and the surface roughness of the rolled strips, as functions of process variables like tangential speed of the rolls, strip speed, flow stress of the strip material, lubricant viscosity as a function of pressure and temperature, and geometric parameters like the roll diameter and the initial and final thickness of the strips.

\section{Nomenclature}

$a \quad=$ rolls radius

C = integration constant

$h \quad=$ thickness of the lubricant film

$h_{1} \quad=$ thickness of the lubricant film in the inlet zone

$k=$ thermal conductivity of the lubricant

$K_{\sigma} \quad=$ strength coefficient

$n \quad=$ strain hardening coefficient

$p \quad=$ pressure in the film

$R \quad=$ reduction of cross section

$R a \quad=$ mean roughness

sd $\quad=$ standard deviation

$s \quad=$ volumetric specific heat of the strip material

$S \quad=$ Somerfeld number

$T=$ film temperature (relative to the rolls temperature)

$U \quad=$ relative speed between the surfaces or speed of the strip in the work zone

$U_{I} \quad=$ speed of the strip in the inlet zone

$U_{r} \quad=$ tangential speed of the rolls

$x=$ position in the contact arc (related to the symmetry line)

$x_{1} \quad=$ length of the contact arc

$x_{2} \quad=$ position at the exit of the work zone

$y_{1} \quad=$ initial thickness of the strip

$y_{2} \quad=$ final thickness of the strip

$w_{1}$ and $w_{2}=$ speeds in direction $z$ (film thickness)

$U_{1}$ and $U_{2}=$ speeds in direction $x$ (rolling direction)

$V_{1}$ and $V_{2}=$ speeds in direction $y$ (strip width)

\section{Greek Symbols}

$\alpha=$ sensitivity coefficient to temperature variation

$\gamma \quad=$ sensitivity coefficient to pressure variation

$\eta \quad=$ dynamic viscosity of the lubricant

$\eta_{0} \quad=$ lubricant dynamic viscosity at ambient pressure and temperature

$\sigma \quad=$ yield stress of the strip material in the work zone

$\sigma_{0} \quad=$ yield stress of the strip material

$\tau \quad=$ shear stress

\section{Subscripts}

1 and 2 = surfaces in contact 


\section{Analysis of Lubrication in Cold Rolling}

\section{Geometric Model}

Figure 1 represents cold rolling of strips with hydrodynamic lubrication.

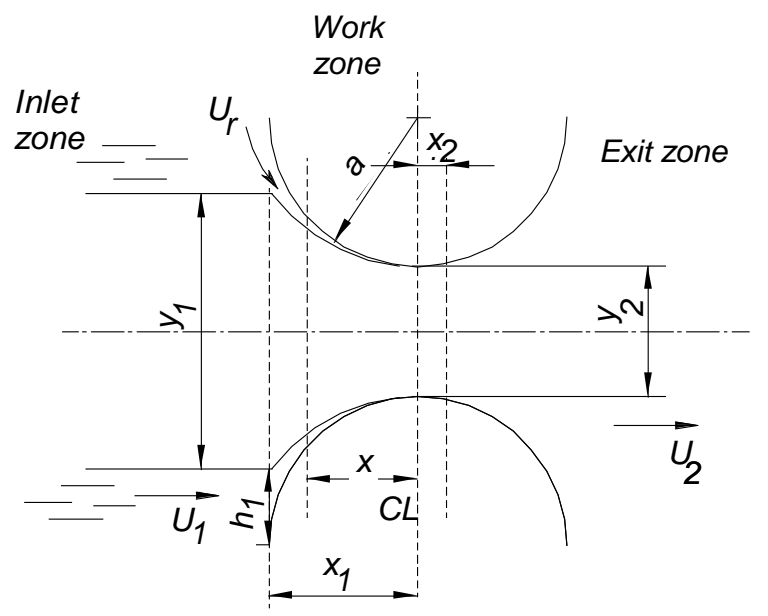

Figure 1. Cold rolling with hydrodynamic lubrication.

\section{Analysis of the cold rolling process}

As shown in Fig. 1 there are three zones that represent the strip during rolling:

Inlet zone. In that zone the strip remains rigid and the lubricant film is rapidly pressurized from the ambient pressure to the pressure at the entrance of the work zone (equal to the yield stress of the strip material).

The film thickness is considerably reduced from some tenths of millimeters to some micrometers due to the pressure gradient and to the increase in the film temperature caused by the lubricant viscous shearing.

Process conditions like cross section reduction, initial viscosity of the lubricant and rolls speed will determine whether this thickness $\left(h_{l}\right)$ will be large enough to get the surfaces apart and to establish the hydrodynamic lubrication.

Work zone. In that region the strip material becomes plastic. The lubricant film is dragged into the interface strip-rolls and is forced by the rolling pressure. Its thickness is reduced and the lubricant viscosity is modified by the pressure variation and by the increase of temperature due to the dissipation of the heat generated by deformation.

The characteristics of the lubricant viscosity, a function of the variation of pressure and temperature, associated to the film thickness, will define the lubrication regime in the work zone: hydrodynamic with thick film, hydrodynamic with thin film, boundary lubrication or mixed (boundary and hydrodynamic), Wilson (1979).

Somerfeld (1961) defines an expression that relates some variables of the process and predicts the lubrication regime:

$$
S=\frac{U \eta}{\sigma} R
$$

The parameter $S$ can be represented as shown in Fig. 2. With low speeds (low $S$ ), the amount of lubricant dragged to the interface is very small, and a few atomic layers of lubricant are in the interface.

With speed increase, intermediate values of $S$, more lubricant is carried to the interface filling the valleys and separating the surface peaks, and establishing the mixed lubrication.

Above a critical value of $S$ the hydrodynamic regime with thin film is established and the surfaces are completely separated by a continuous and uniform film.

At high speeds, and high $S$ values, a hydrodynamic regime with thick film is established and the viscous shearing is increased.

The pressurized lubricant film modifies strip surface roughness. Wilson (1977) and Mizuno and Hasegawa (1982) have shown that in strip compression tests the establishment of a hydrodynamic regime modifies the surface texture of the deformed material by two mechanisms. Ratnagar et al. (1974) presented similar results for the compression of cylinders.

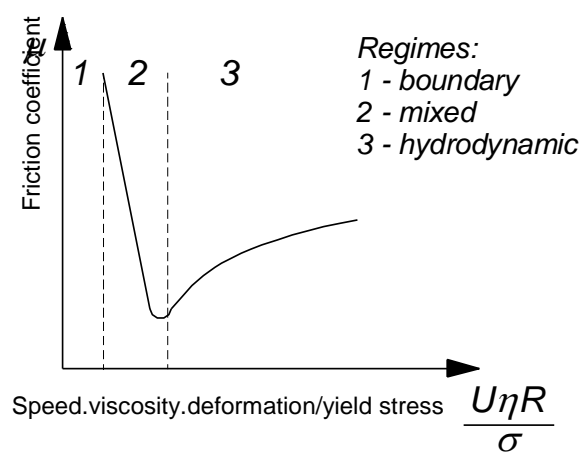

Figure 2. Stribeck's curve, adapted from Bowden-Tabor (1954).

With low viscosity lubricants this texture modification is due to the differential deformation of individual crystalline grains. This mechanism is more easily observed during formation of quasiisotropic materials with coarse grains, like in cold rolling of hot rolled strips.

With more viscous lubricants the texture modification is due to the indentation caused by the pressurized film, associated to the differential deformation of the grains. In this case, the modification is more pronounced than in the first mechanism, and the mean roughness $(R a)$ can be related to the film thickness in the work zone $\left(h_{1}\right)$, as follows:

$$
R a=0.25 h_{1}
$$

Exit zone. In that region the strip becomes rigid again. The film thickness is slightly reduced and the pressure in the film drops to the ambient pressure. The passage from the work zone to the exit zone occurs at a position $\left(x_{2}\right)$ anterior to the line that links the centers of the rolls $(C L)$.

Analysis of hydrodynamic lubrication in strip cold rolling inlet zone

Equation (3) presented by Reynolds (Cameron, 1966) for the tridimensional case is obtained if assumed that: 
- inertia forces are negligible, because there are no external forces related to gravitational, magnetic or electrical fields acting on the lubricant;

- pressure is constant along film thickness. This hypothesis is valid if the film thickness is assumed to be very small;

- surfaces in contact are much larger than the film thickness, and, therefore, fluid flow is negligible in the thickness direction;

- there is no sliding among the surfaces (tool and workpiece) and the lubricant film, i.e. each surface presents the same speed of the adjacent lubricant layer;

- the lubricant is considered a "Newtonian" fluid. This hypothesis is valid to fluids commonly used in cold rolling at pressures around $1000 \mathrm{MPa}$;

- lubricant flow is laminar, considering that rolling speed is high enough and that the interface rolls-strip is relatively small;

- fluid inertia is neglected. Even for conditions with high Reynolds number, around one thousand for example, pressure is slightly modified and the fluid inertia is considered.

$\frac{\partial}{\partial x}\left(\frac{h^{3}}{\eta} \frac{\partial p}{\partial x}\right)+\frac{\partial}{\partial y}\left(\frac{h^{3}}{\eta} \frac{\partial p}{\partial y}\right)=6\left\{\frac{\partial}{\partial x}\left(U_{1}+U_{2}\right) h+\frac{\partial}{\partial y}\left(V_{1}+V_{2}\right) h+2\left(w_{1}-w_{2}\right)\right\}$

In strip rolling it can be assumed that:

- dimension in direction $y$ is many times larger than in direction $x$, and therefore fluid flow in direction y can be neglected, and then $\frac{\partial p}{\partial y}=0$

- $V_{1}=V_{2}=0$ because strip width is not modified during rolling (plane deformation);

- surfaces do not move in direction $z$ and therefore $w_{1}=w_{2}=0$ Eq. (4):

Considering these hypotheses, Eq. (3) can be rewritten giving

$$
\frac{d}{d x}\left(\frac{h^{3}}{\eta} \frac{\partial p}{\partial x}\right)=6\left\{\frac{d}{d x}\left(U_{1}+U_{2}\right) h\right\}
$$

Integrating Eq. (4) in respect to $x$ and considering that $h$ and $\eta$ are functions of the position along the rolling direction in the inlet zone:

$$
\frac{h^{3}}{\eta} \frac{d p}{d x}=6\left(U_{1}+U_{r}\right) h+C
$$

Just before the entrance of the work zone, film pressure is equal to ambient pressure $\left(\frac{d p}{d x}=0\right)$, film thickness equals to $h_{l}$ (Fig.1) and $C$ can be calculated:

$$
C=-6\left(U_{1}+U_{r}\right) \eta h_{1}
$$

Considering that axis $\mathrm{x}$ is opposite to the rolling direction in the inlet zone, Eq. (5) becomes:

$$
\frac{d p}{d x}=6 \eta\left(U_{1}+U_{r}\right)\left(\frac{h_{1}-h}{h^{3}}\right)
$$

When the lubricant flows under high pressures and temperatures, dynamic viscosity can be considered as of both variables (Bair and McCabe, 2007) and assumed as shown in Eq. (8):

$$
\eta=\eta_{0} e^{p-\alpha T}
$$

With a first approximation to simplify the calculus of $h_{l}$, it was assumed that the viscosity in the entrance zone is dependent only on the pressure variation. This is a suspicious assumption since the heat generation by viscous shearing in that zone could not be negligible (Dow et al., 1975), as will be shown in this work.

With this assumption, Eq. (8) and Eq. (7) become respectively:

$$
\begin{aligned}
& \eta=\eta_{0} e^{\eta p} \\
& e^{-\eta p} \frac{d p}{d x}=6 \eta_{0}\left(U_{1}+U_{r}\right)\left(\frac{h_{1}-h}{h^{3}}\right)
\end{aligned}
$$

At the entrance of the work zone, strip becomes plastic and pressure equals to the yield stress of the strip material. Integrating Eq. (10) $h_{l}$ can be calculated:

$$
h_{1}=\frac{3 \eta_{0} \gamma\left(U_{1}+U_{r}\right)}{\left(1-e_{0}^{\gamma \sigma}\right)} \sqrt{\frac{a}{R y_{1}}}
$$

Boundary conditions for Eq. (11) are shown in the section "Materials and Methods - Rolling tests".

With $h_{l}$ it can be written Eq. (12) which relates the pressure $(p)$ in the entrance zone with the film thickness $(h)$ :

$$
\frac{d p}{d h}=6 \eta_{0}\left(U_{1}+U_{r}\right)\left(\frac{h_{1}-h}{h^{3}}\right) \frac{a}{x_{1}} R^{\prime} e^{2 p}
$$

where is $\mathrm{R}^{\prime}$ is a coefficient adopted to consider the influence of thermal effects (Eq. (13)) (Wilson and Mahdavian, 1974):

$$
R^{\prime}=\left(1+0,5 F^{0.855}+0.05 S^{0.773}\right)^{-1}
$$

where

$$
F=\frac{\eta_{0} e^{r p} \alpha\left(U_{1}+U_{r}\right)^{2}\left(h-h_{1}\right)^{2}}{4 k h^{2}}
$$

and

$$
S=\frac{\eta_{0} e^{\not p} \alpha\left(U_{1}+U_{r}\right)^{2}}{k}
$$

Rewriting Eq. (12) with $F$ and $S$ as dimensionless numbers, we have Eq. (16):

$$
\frac{d B}{d H}=\frac{2 G R^{\prime}(H-1)}{H_{1} H^{3}}
$$

with

$$
\begin{array}{ll}
B=e^{\imath p} & H=h / h_{1} \\
H_{1}=\frac{h_{1} \sigma_{0} x_{1}}{3 \eta_{0} a\left(U_{1}+U_{r}\right)} &
\end{array}
$$




$$
G=\gamma \sigma_{0} \quad F=L \frac{(H-1)^{3}}{B H^{3}}
$$

and

$$
S=4 L \frac{(1-Z(1-R))^{2}}{B(1+Z(1-R))^{2}}
$$

with

$$
L=\frac{\eta_{0} \alpha\left(U_{1}+U_{r}\right)^{2}}{4 k}
$$

where

$$
Z=U_{2} / U_{r} \quad \text { and } \quad R=1-y_{2} / y_{1}
$$

The boundary conditions that will be applied to Eq. (16) are defined as follow: in the entrance of the inlet zone, where the film thickness is very large if compared to $h_{l}$ and the pressure in the film equals to the ambient pressure, $h=\infty$ and $p=0$, or in dimensionless terms $H=\infty$ and $B=1$. In the passage from the inlet zone to the work zone, $h=h_{l}$ and $p=\sigma_{0}$ or $H=1$ and $B=e^{-G}$.

\section{Analysis of the work zone}

In the work zone the expression that relates the pressure with the film thickness, as a function of the position along this region, is determined by the slab method, first defined by Sachs. In this work, the work zone is represented as shown in Fig. 3(a).

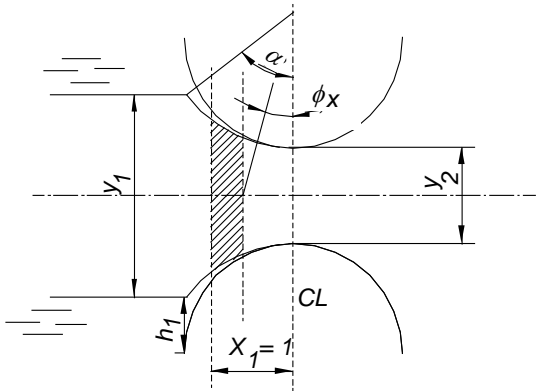

(a)

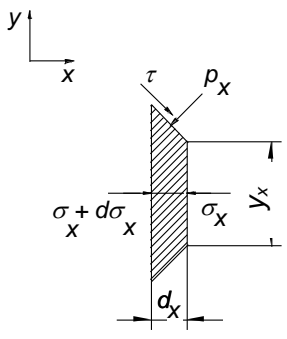

(b)
Figure 3. (a) Representation of the work zone with backward slip, and (b) Forces equilibrium within an infinitesimal slab.

Equation (17) presents the forces equilibrium in the work zone with backward slip, i.e., the region between the entrance of the work zone and the neutral line, where the strip surface tends to slip in the opposite direction to the rotation of the rolls, and, as consequence, the tangential stress $(\tau)$ caused by friction is in the rolling direction (Tselikov, 1962).

$$
d \sigma_{x}-\left(\frac{2 \sigma_{0}}{\sqrt{3}}+\frac{\tau}{\tan \phi}\right) \frac{d y}{y}=0
$$

In this method the loads acting on one slab are balanced (Fig. $3(\mathrm{~b}))$. The shear stress $(\tau)$ in the interface roll-strip is defined in this model by Eq. (18), defined by Newton (Cameron, 1966) for "Newtonian" fluids as a function of lubricant viscosity $(\eta)$, relative speed $(U)$ and film thickness $(h)$ :

$$
\tau=\frac{\eta U}{h}
$$

With Eq. (8) adopted to represent $\mathrm{h}$ and using dimensionless terms to substitute $\mathrm{x}, \mathrm{y}, \mathrm{p}$ and $\mathrm{h}, \mathrm{Eq}$. (19) relates the pressure and the film thickness with the position in the work zone, and has been modified from Wilson and Walowit (1971) to include the thermal influence on the lubricant viscosity in the work zone.

$$
Y \frac{d B}{d X}+G B \frac{d Y}{d X}-\frac{2 R F^{\prime} G(Y-Z(1-R))}{3 H_{1} H Y(1+Z(1-R))}
$$

where

$$
\begin{aligned}
& X=x / x_{1} \\
& Y=y / y_{1} \\
& Y=1-R+R X^{2} \quad \frac{d Y}{d X}=2 R X \\
& F^{\prime}=\frac{2 C_{1}(1-\phi)^{2}}{\left[S(1-\phi)^{2}+8\right]^{1 / 2}\left[S(1-\phi)^{2}+8 \phi^{2}\right]^{1 / 2}} \\
& C_{1}=4 \ln \left\{\left[\frac{S(1-\phi)^{2}+8 \phi^{2}}{8(1-\phi)^{2}}\right]^{1 / 2}+\left[\frac{S(1-\phi)^{2}+8}{8(1-\phi)^{2}}\right]^{1 / 2}\right\} \\
& \phi=\tanh (D / 4) \\
& K=\frac{\alpha \sigma}{S}
\end{aligned}
$$

where

$$
\begin{aligned}
& S=4 L \frac{(Y-Z(1-R))^{2}}{B Y^{2}(1+Z(1-R))^{2}} \\
& H=\frac{Y(1+Z(1-R))}{2 Y+2 W(Z(1-R)-Y)} \\
& W=\frac{e^{D}-D-1}{D\left(e^{D}-1\right)}
\end{aligned}
$$

In this work it was assumed that the strip material presents a hardening behavior expressed by Eq. (20):

$$
\sigma=K_{\sigma} \varepsilon^{n}
$$

The boundary conditions necessary to the solution of Eq. (19) are shown as follow.

In the passage from the inlet zone to the work zone, $x=x_{I}$ and $p=\sigma$, or $X=1$ and $B=e^{-G}$.

At the exit of the work zone $x=x_{2}$ and $p=\sigma$, or $X=X_{2}$ and $B=$ $e^{-G}$ with $X_{2}=x_{2} / x_{1}$, and $X_{2}$ can be determined by Eq. (21) described by Wilson and Walowit (1971):

$$
X_{2}=\left\{\frac{27}{4}\left[\frac{(1+Z(1-R))^{3}}{(1+Z)^{2}}\right] A^{2}\right\}^{1 / 3}
$$


where

$$
A=\frac{\eta_{0} a^{2} U_{r}}{x_{1}^{3}}
$$

\section{Materials and Methods}

\section{Rolling tests}

Laboratory rolling tests were carried out in a duo-reversible rolling mill with the following characteristics:

- rolls diameter: $135 \mathrm{~mm}$

- rolls surface roughness: $\mathrm{Ra}=0.52 \mu \mathrm{m}$ (mean of four measurements with standard deviation $(s d)$ equal to $0.08 \mu \mathrm{m}$ )

- variable rolling speed from 5 to $30 \mathrm{~m} / \mathrm{min}$

- nominal power: $19 \mathrm{~kW}$

The material of the workpieces was a commercial aluminum alloy (AA 1100) with the following properties:

- workpiece dimensions: 150 x 12.6 x 51 mm (length $\mathrm{x}$ thickness $\mathrm{x}$ width)

- equiaxial grains with mean size of $0.03 \mathrm{~mm}$

- Vickers hardness: $\mathrm{HV}_{5.0}=64.5$

- flow curve: $\sigma=174 . \varepsilon^{0.30}[\mathrm{MPa}]$

- volumetric specific heat: $s=2.43 .10^{4} \mathrm{~J} /\left(\mathrm{m}^{3} . \mathrm{K}\right)$

- surface roughness:

$\mathrm{Ra}=0.24 \mu \mathrm{m}$ in the rolling direction

(mean of five measurements with $s d=0.06 \mu \mathrm{m}$ )

$\mathrm{Ra}=0.72 \mathrm{~mm}$ in the transversal direction

(mean of five measurements with $s d=0.09 \mu \mathrm{m}$ )

Three lubricants were used and their properties are shown in Table 1. Those lubricants were chosen to analyze the influence of the viscosity on the lubrication regimes.

Table 1. Properties of the three lubricants used in the rolling tests.

\begin{tabular}{|c|c|c|c|}
\hline Lubricant & $\begin{array}{c}\text { Viscosity } \\
\left(\eta_{0}\right) \\
{\left[\mathrm{N} . \mathrm{s} / \mathrm{m}^{2}\right]}\end{array}$ & $\begin{array}{c}\text { Pressure } \\
\text { coefficient }(\gamma) \\
{\left[10^{-8} \mathrm{~m}^{2} / \mathrm{N}\right]}\end{array}$ & $\begin{array}{c}\text { Temperature } \\
\text { coefficient }(\alpha) \\
{\left[{ }^{\circ} \mathrm{C}^{-1}\right]}\end{array}$ \\
\hline Emulsion oil & 0.3 & 0.7 & 0.0625 \\
\hline $\begin{array}{c}\text { MJF-2 } \\
\text { (mineral oil) }\end{array}$ & 1.3 & 1.2 & 0.071 \\
\hline $\begin{array}{c}\text { MJF-5 } \\
\text { (mineral oil) }\end{array}$ & 3.1 & 2.0 & 0.107 \\
\hline
\end{tabular}

Two area reduction per rolling pass were used, the first equal to $12.7 \%$ with strip thickness varying from $12.6 \mathrm{~mm}$ to $11 \mathrm{~mm}$, and the second reduction equal to $20.6 \%$ (from 12.6 to $10 \mathrm{~mm}$ in thickness).

Two different speed ranges were tested: one between 0.08 and $0.17 \mathrm{~m} / \mathrm{s}$, and other between 0.42 and $0.5 \mathrm{~m} / \mathrm{s}$, to analyze the influence of rolling speed on the lubrication regime. These speeds are common in industrial practice to cold rolling of aluminum strips.

\section{Tests with rolled products}

To analyze how rolling conditions influenced surface texture of the rolled strips, it was measured the mean surface roughness Ra. The measurements were done in the rolling direction and in the transversal direction, in three zones along the workpiece, each one with three measurements in three regions in a total of 54 measurements per workpiece.

\section{Results and Discussion}

A computational program with the equations of this model was written to simulate the rolling tests with the parameters shown in Table 2.

Table 2. Parameters used in the simulation of the rolling tests.

\begin{tabular}{|c|}
\hline$a=67.5 \mathrm{~mm}$ \\
\hline$U_{1}=0.01 \mathrm{~m} / \mathrm{s}$ \\
\hline$U_{r}=0.17 \mathrm{~m} / \mathrm{s}$ or $U_{r}=0.5 \mathrm{~m} / \mathrm{s}$ \\
\hline$y_{1}=12.6 \mathrm{~mm}$ \\
\hline$y_{2}=10 \mathrm{~mm}$ or $y_{2}=11 \mathrm{~mm}$ \\
\hline
\end{tabular}

\section{Analysis of pressure and film thickness variation}

Figures 4 and 5 show the variation of the pressure and film thickness in the inlet zone, as a function of the iteration number used to solve the Eq. (16). It can be observed that the pressure is largely increased near the border inlet zone-work zone, and as a consequence, the lubricant is pressurized and dragged to the work zone forming a continuous film.

The film thickness is reduced from the initial thickness (some tenths of millimeters) to $h_{l}$ (some thousandths of millimeters).

Figure 6 shows the variation of the film thickness in the entrance of the work zone $\left(h_{l}\right)$ as a function of lubricant viscosity. Large values of $h_{l}$ are associated to the establishment of a continuous film, stable and thick enough to separate the surfaces, and reduce the friction. As observed in Fig. 6 high large values of $h_{l}$ are found for high viscosity and rolling speeds.

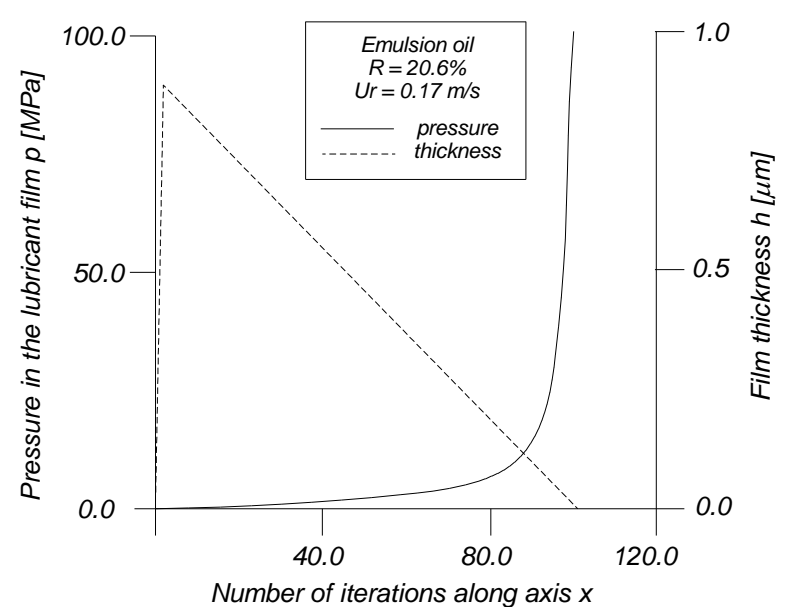

Figure 4. Variation of pressure and film thickness in the inlet zone.

With speed increase, the viscous drag effect is enhanced and more lubricant is carried to the entrance of the work zone, the viscous shearing is also enhanced with more heat being generated and dissipated in the film, reducing lubricant viscosity and consequently its thickness, unstabilizing and breaking out the film.

With more viscous lubricants, less sensible to viscous shearing and temperature increase, proper lubrication conditions are achieved establishing a thick, uniform and continuous film. 


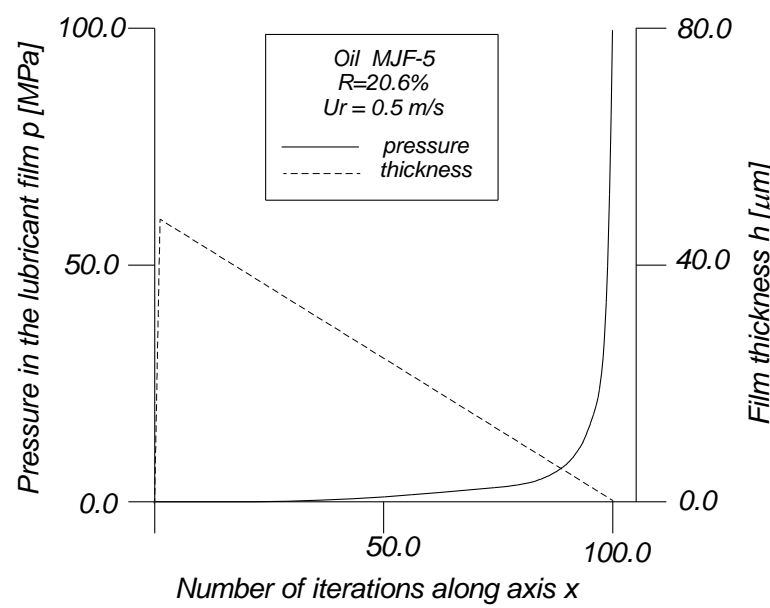

Figure 5. Variation of pressure and film thickness in the inlet zone.

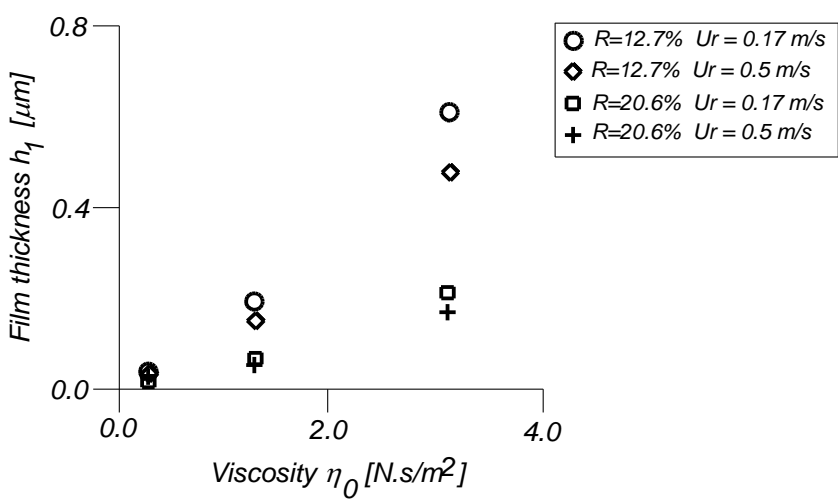

Figure 6. Variation of pressure and film thickness in the entrance of the work zone, as a function of the lubricant viscosity.

It can also be observed as a result of this study that the area reduction does not affect significantly $h_{l}$ which is more sensible to variations in lubricant viscosity and rolling speed.

Figures 7 and 8 show the variation of pressure and film thickness as function of the position along the work zone $(x)$. It can be observed that the thickness is continuously reduced towards the exit of the work zone $(x=0.0)$ as a result of temperature increase due to the dissipation of the heat generated by the deformation and variation of lubricant pressure.

The aspect of the curves is different in each case. In Fig. 7, for the results with emulsion oil, it is observed an initial drop of the pressure to a minimum at low speeds. The pressure increases again to the exit of the work zone, with a maximum variation equal to $8 \%$. Tselikov (1967) states that this pressure profile is characteristic in strip rolling with lubrication, where the tangent of the angle of contact for any position $x\left(\tan \phi_{x}\right)$ is always greater than the friction coefficient $\mu$.

Therefore, it can be concluded that despite the small film thickness observed in Fig. 6, the lubricant can reduce the friction and establish this pressure profile.

Figure 8 shows the results with the oil MJF-5 more viscous and at a greater speed. It can be observed a similar pressure profile, but with a less pronounced decrease of the pressure near the entrance of the work zone.

This behavior is also explained by the theory of Tselikov, since in this case, as observed in Fig. 6, the lubricant film is thicker $\left(h_{l} \approx\right.$ $0.5 \mu \mathrm{m})$. Thus, associated to a viscous lubricant less sensitive to pressure and temperature variations, a continuous and thick film will be formed and kept along this work zone. Therefore the friction coefficient is significantly reduced and the pressure shows a small increase (around $4 \%$ ) with a less pronounced profile.

Dow et al. (1975) analyzed the pressure variation in the rolling of steel and aluminum strips and obtained profiles similar to those obtained in this work.

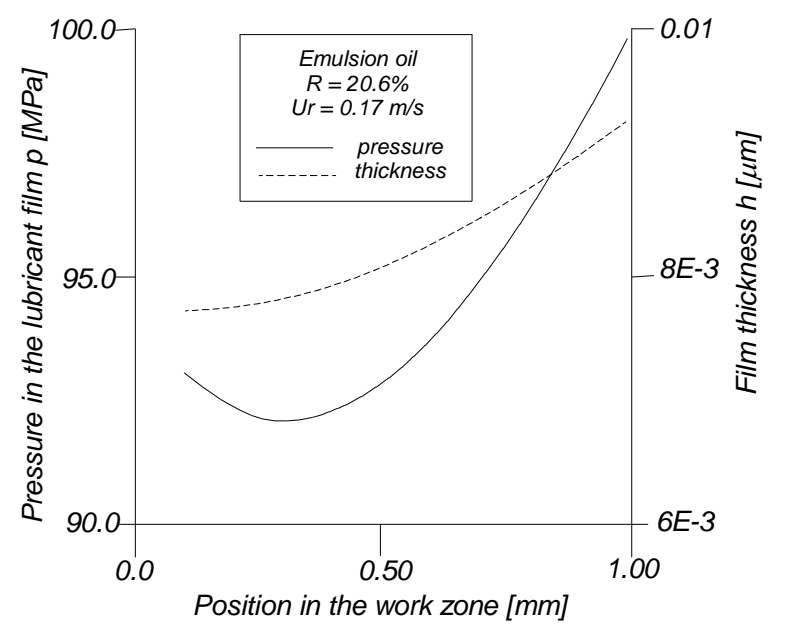

Figure 7. Results for the pressure and film thickness as functions of the position in the work zone.

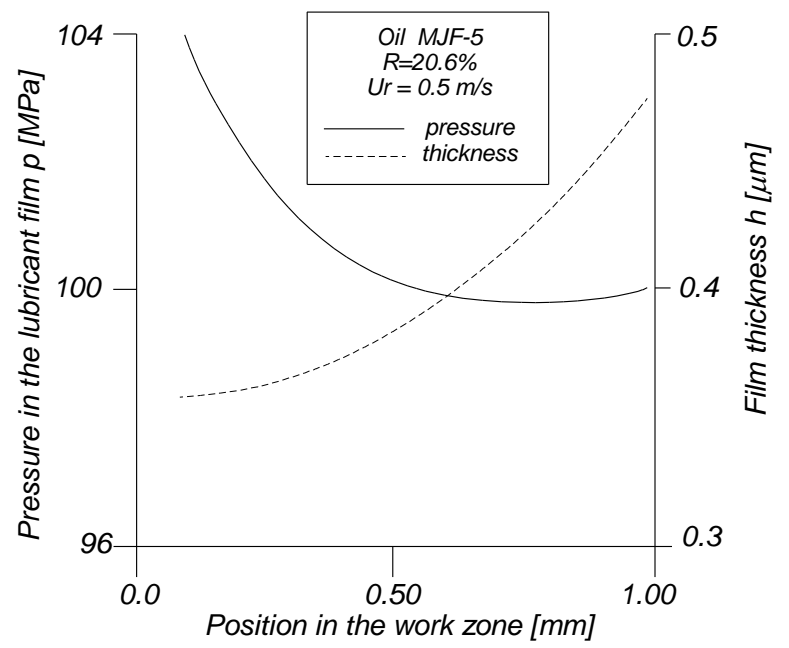

Figure 8. Results for the pressure and film thickness as functions of the position in the work zone.

\section{Analysis of surface roughness of the rolled products}

Figures 9 and 10 show experimental results of the surface roughness $(\mathrm{Ra})$ of rolled products and raw material. It can be observed that surface roughness is reduced as the rolling speed increases, regardless of the area reduction. This reduction is more intense when it is analyzed the effect of lubricant viscosity on the roughness. These results are apparently opposite to the theory stated by Wilson (1977), who relates the surface texture to the hydrodynamic lubrication. This conclusion could be explained considering that rolling tests carried out in this work presented a lubrication regime in the transition region between mixed and hydrodynamic lubrication (Fig. 2), so the film thickness would be thick enough to reduce rolling load, but not enough to prevent strip 
surface being directly deformed by rolls, and therefore reproducing rolls surface texture and roughness.

Rolling tests with more viscous lubricants and high speeds should present products with high roughness due to the deformation caused by the indentation of the surface by the viscous pressurized lubricant and by the differential deformation of individual grains in the surface.

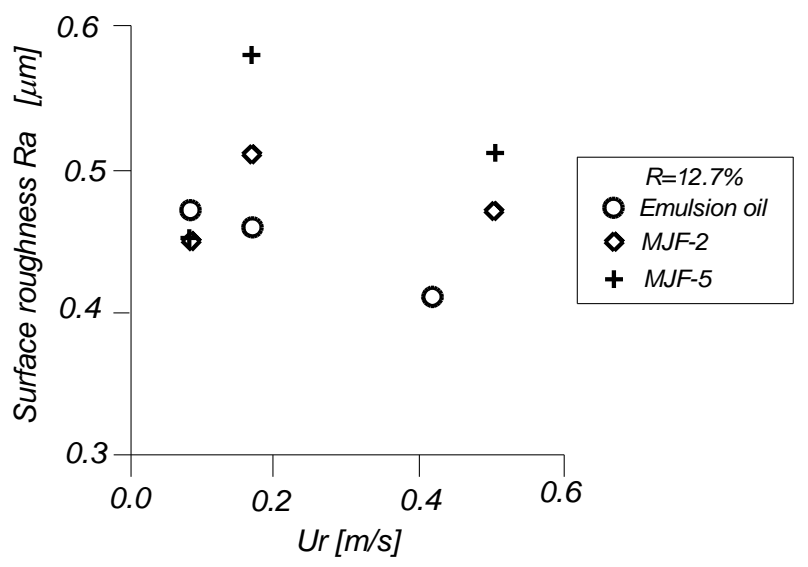

Figure 9. Surface roughness of the rolled products as a function of the rolling speed.

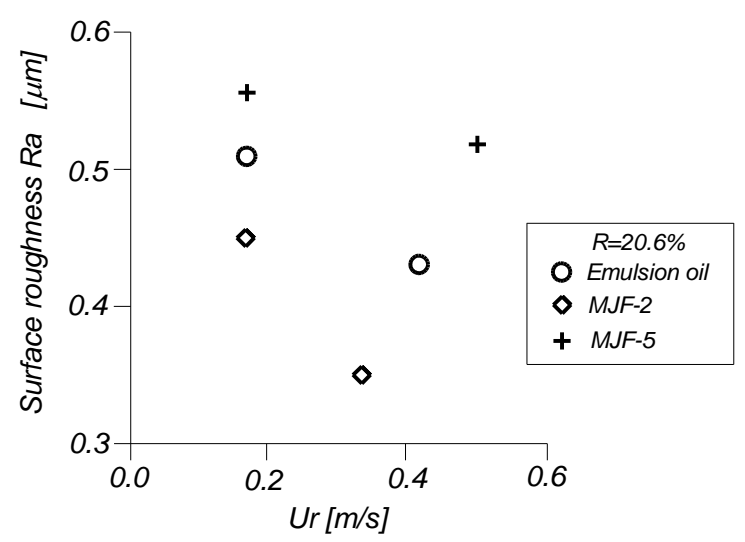

Figure 10. Surface roughness of the rolled products as a function of the rolling speed.

The surface texture of the raw material shows grooves parallel to the rolling direction that are characteristic of the previous hot rolling. Products rolled with emulsion oil, $0.17 \mathrm{~m} / \mathrm{s}$ and area reduction of $12.7 \%$ presented a texture common to cold rolling with lubrication, consisting of parallel grooves perpendicular to the rolling direction. By the theory of Wilson, those grooves are formed by the differential deformation of the grains and should present a small depth, and consequently a small surface roughness.

It can also be observed that the original hot rolling texture was not completely modified by the cold rolling, since there are still some longitudinal grooves that cause roughness increase.

Again, for products rolled with the lubricant MJF-2 (medium viscosity), $0.5 \mathrm{~m} / \mathrm{s}$ and $20.6 \%$ in area reduction, it was observed a texture similar to the raw material, with parallel grooves and some small grooves from the previous hot rolling. The parallel grooves are also formed by the differential deformation of the grains and might show a high depth since this test conditions presented a higher value for the film thickness $h_{l}$.

The texture of products rolled with MJF-5 (high viscosity), 0.5 $\mathrm{m} / \mathrm{s}$ and area reduction of $20.6 \%$ is directly related to pressurized high viscosity lubricants that form spaced grooves and dispersed spots. The grooves from the previous hot rolling are not observed, what means that the surface texture was completely modified by the hydrodynamic lubrication with thick film.

Figures 11 and 12 show the surface roughness of the rolled products compared to the surface roughness of the rolls and raw material. It can be observed that the products showed a uniform texture, since the values of the longitudinal and transversal roughness are similar. The mean longitudinal roughness of these products is less than the rolls roughness, but higher than the raw material, what can be explained by the parallel grooves formed by the hydrodynamic lubrication.

The mean transversal roughness was higher than the rolls roughness and similar to the transversal roughness of the raw material, since for many rolling conditions the transversal grooves from the hot rolling were still present.

If the surface roughness $\mathrm{Ra}$ of the products is compared to the results of film thickness $h_{l}$ (Fig. 6), it can be observed that the relation stated by Wilson (1977), $R a=0.25 h_{1}$, is satisfied for the rolling conditions used in this work.

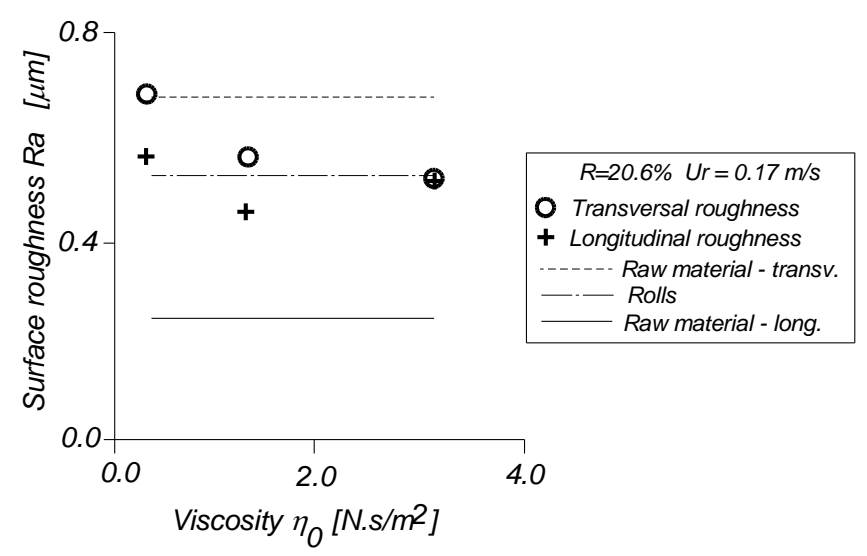

Figure 11. Longitudinal and transversal surface roughness $\mathrm{Ra}$ of rolled products, rolls and raw material.

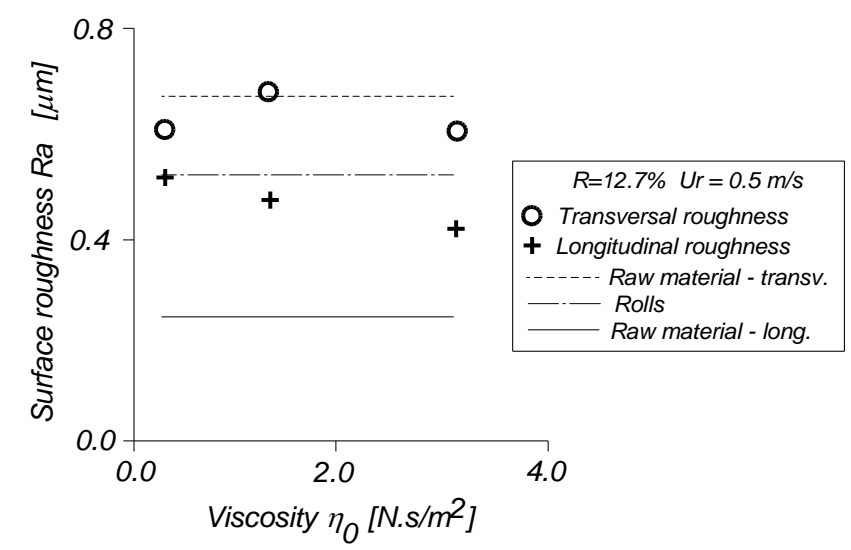

Figure 12. Longitudinal and transversal surface roughness $\mathrm{Ra}$ of rolled products, rolls and raw material.

\section{Conclusion}

From the analysis of the numerical results obtained with the mathematical model proposed in this work and compared to experimental results obtained in the strip rolling tests it can be concluded: 
- a thick, uniform and continuous film is formed and a proper lubrication is achieved with viscous lubricants, less sensitive to viscous shearing and temperature increase;

- area reduction does not affect significantly the film thickness at the entry of the inlet zone which is more sensible to variations in lubricant viscosity and rolling speed;

- a continuous and thick film will be formed and kept along the work zone with viscous lubricant less sensitive to pressure and temperature variations;

- surface roughness of rolled strip is reduced as the rolling speed increases, regardless of the area reduction;

- tests with more viscous lubricants and high speeds present products with high roughness due to the deformation caused by indentation of the surface by the viscous pressurized lubricant and by differential deformation of individual grains near to the strip surface;

- surface texture of the raw material can be partially or totally modified depending mainly on lubricant viscosity and rolling speed.

\section{Acknowledgements}

The author thanks FAPESP (Fundação de Amparo à Pesquisa do Estado de São Paulo) and CNPq (Conselho Nacional de Desenvolvimento Científico e Tecnológico) for the financial support to this work.

\section{References}

Bair, S. and McCabe, C., Tribology and Interface Engineering Series, Vol. 54, High-Pressure Rheology for Quantitative Elastohydrodynamics, cap. 6: Models for the temperature and pressure dependence of low-shear viscosity, 2007, $101 \mathrm{p}$.

Bowden-Tabor, 1954, "The Friction and Lubrication of Solids", Oxford and the Clarenden Press, London, Part I.

Bedi, D.S. and Hillier, M.J., 1968. "Hydrodynamic Model for Cold Strip Rolling”, Proc. Inst. Mech. Eng., vol. 182, part I, pp. 158-162.

Cameron, A., 1966, "The Principles of Lubrication", chapter 2, 1st ed., Longmans Green \& Co., London.

Cheng, M.S., 1966, "Plastohydrodynamic Lubrication, Friction and Lubrication in Metal Processing", ASME, New York, pp. 69-89.
Dow, T.A., Jannel, J. and Bupara, S.S., 1975, "A Hydrodynamic Lubrication Theory for Strip Rolling Including Thermal Effects", Trans. of ASME, J. of Lub. Tech., January, pp. 4-14.

Kosasih, P.B. and Tieu, A.K., 2007, "Mixed Film Lubrication of Strip Rolling Using O/W Emulsions", Tribology International, Vol. 40, No. 5, pp. 709-716.

Louaisil, K., Dubar, M., Deitombe, R., Dubois, A. and Dubar, L., 2009, "Analysis of Interface Temperature, Forward Slip and Lubricant Influence on Friction and Wear in Cold Rolling", Wear, Vol. 266, No. 1-2, pp. 119-128.

Mizuno, T. and Hasegawa, K., 1982, "Effects of Die Surface Roughness on Lubrication Conditions in the Sheet Metal Compression-friction Test", Trans. of ASME, J. of Lub. Tech., pp. 23-28.

Ratnagar, D.D., Cheng, H.S. and Schey, J.A., 1974, "Surface Deformation of Aluminum Compressed with Viscous Lubricants, Trans. of the ASME, October, pp. 591-594.

Singh, P., Pandey, R.K. and Nath, Y., 2008, "An Efficient Thermal Analysis for the Prediction of Minimum Film Thickness in Inlet Zone at High Speed Lubricated Cold Strip Rolling", J. of Materials Processing Technology, Vol. 200, No. 1-3, pp. 238-249.

Sommerfeld, A., 1961, "Zur Hydrodynamischen Theorie der Schmiermittelreibung", Z. Math. und Physik, Vol. 50, p. 97, 1904 in Pinkus, O. and Sternlicht, B., "Theory of Hydrodynamic Lubrication", McGraw Hill Book Co.

Tselikov, A., 1967. "Stress and Strain in Metal Rolling", Mir Publishers, Moscow.

Wei, D.B., Jiang, Z.Y., Lu, C., Tang, Y. and Tieu, A.K., 2009, "Experimental Study of the Effects of Rough Texture on Surface Deformation During Cold Metal Forming", Wear, Vol. 267, No. 9-10, pp. 1746-1751.

Wilson, W.R.D., 1977, "Workpiece Surface Roughening in a Hydrodynamically Lubricated Metal Forming Process", Trans. of ASME, January, pp. 10-14.

Wilson, W.R.D., 1979, "Friction and Lubrication in Bulk Metal Forming Processes", J. of App. Metalworking, Vol. 1, No. 1, pp. 7-9.

Wilson, W.R.D. and Mahdavian, S.M., 1974, "A Thermal Reynolds Equation and its Application in the Analysis of Plasto-hydrodynamic Inlet Zones", Trans. of ASME, J. of Lub. Techn., Vol. 96, No. 4, pp. 572-578.

Wilson, W.R.D. and Murch, L.E., 1976, "A Refined Model for the Hydrodynamic Lubrication of Strip Rolling", Trans. of ASME, J. of Lub. Tech., July, pp. 426-432.

Wilson, W.R.D. and Walowit, J.A., 1971, "An Isothermal Hydrodynamic Theory for Strip Rolling with Front and Back Tension", Tribology Convention, I. M. Eng., London, pp. 169-172. 